\title{
Implementasi RFID dan NodeMCU Untuk Data Kunjungan Perpustakaan Berbasis IoT
}

\author{
Amri Yahya Khadafi, Ucuk Darusalam, Winarsih \\ Fakultas Teknologi Komunikasi dan Informasi, Informatika, Universitas Nasional, Indonesia \\ Email: 1"amrikers58@gmail.com, ${ }^{2}$ ucuk.darussalam@email.com, ${ }^{3}$ winarsih@civitas.unas.ac.id
}

\begin{abstract}
Abstrak-Radio Frequency Indentification (RFID) melakukan identifikasi otomatis dengan cara menyimpan dan mengirim data secara nirkabel melalui kartu RFID atau transponder. Beragam aplikasi mutakhir dari RFID sudah banyak digunakan berbagai sektor kehidupan terutama kaitannya dengan identifikasi melalui gelombang radio baik di bidang otomotif, biomedik, institusi pendidikan, kepolisian, perbankan, transportasi, dan lain-lain. Tujuan dari penelitian ini adalah melakukan implementasi RFID dalam administrasi perpustakaan, sehingga RFID ini dapat dijadikan solusi alternatif selain barcode sebagai media identifikasi data pengunjung yang tersimpan dalam program basis data melalui dukungan gelombang elektromagnetik. Penelitian dilakukan dengan cara mengidentifikasi data-data pengunjung yang terdaftar di perpustakaan, melakukan perancangan perangkat lunak dan perangkat keras, uji coba sistem, pelaporan, dan publikasi ilmiah. Saat ini kita tahu bahwa perpustakaan universitas nasional masih menggunakan kertas untuk mengisi data kunjungan, untuk mengatasi masalah tersebut hasil dari pengujian menggunakan metode radio frequency identification dan mikrokontroller NodeMCU ini dapat mengirimkan data pengunjung ke aplikasi web dan dapat disimpan ke dalam database, Diharapkan dari hasil pengujian aplikasi ini dapat menyelesaikan masalah yang ada di perpustakaan yang sebelumnya anggota menulis data kunjungan untuk masuk kedepannya hanya perlu tap kartuuntuk masuk dan tidak memerlukan kertas sebagai media registrasi.
\end{abstract}

Kata Kunci: Monitoring, Nodemcu Lolin, MySQL, RFID, PHP.

Abstract-Radio Frequency Identification (RFID), automatic identification by storing and sending data wirelessly via RFID card or transponders. A variety of recent applications of RFID have been developed in various sectors of life, especially related to identification via radio waves both in the field of automotive, biomedical, educational institutions, police, banks, transportation, and others. The purpose of this research is to design an RFID application in the field of libraries, so that RFID can be used as an alternative solution other than the barcode as the media identification data stored neatly in a book database program through the support of electromagnetic waves. At present we know that the national university library still uses paper to fill in the visit, to resolve the issue data from testing using the RFID method and the NodeMCU microcontroller, it can send data to a web application and can be stored in a database, It is expected that from the results of testing this application can solve the problems that exist in the library that previously members wrote a visit data to enter the future only need to tap the card to enter and do not need paper as a registration medium.

Keywords: Monitoring, Nodemcu Lolin, MySQL, RFID, PHP.

\section{PENDAHULUAN}

Monitoring data kunjungan perpustakaan merupakan salah satu faktor penting dalam keamanan perpustakaan, informasi yang di dapat yaitu NPM, Nama dan waktu kunjungan. Tetapi terkadang fungsi data kunjungan perpustakaan dapat dimanipulasi identitas, Hal ini terjadi karena data kunjungan perpustakaan yang masih menggunakan pengisian data manual. Oleh karena itu Penelitian yang dilakukan oleh Kurniawan, A., Syauqy, D., \& Prasetio, B. H N dengan judul Pengembangan Sistem Monitoring Listrik Pada Ruangan Menggunakan NodeMCU dan MQTT NodeMCU dapat diimplementasikan untuk memantau penggunaan listrik pada ruangan [1].

Dengan mengimplementasikan NodeMCU dengan menggunakan framework Node.js dapat melakukan autentikasi terhadap token yang dikirimkan oleh publisher. Ketika publisher token yang tidak valid, server dan broker dapat meng-autentikasi. Ketika token yang digunakan telah expired, broker dan server berhasil melakukan autentikasi dan menampilkan pesan error. Ketika hal ini terjadi maka publisher harus melakukan request ulang token [2]. Perancangan website perpustakaan untuk memberikan informasi Informasi tentang perpustakaan online yang dapat di akses oleh semua orang melalui internet, oleh sebab itu tujuan dari penelitian ini adalah membuat perpustakaan sekolah berbasis web yang dapat memberikan informasi bagi para pengunjung [3]. Agar memudahkan pencarian data perpustakaan pada Sekolah SMK Yadika 13 Tambun Utara merancang website sistem informasi yang dapat mencari data melalui website tanpa mencari data secara manual [4].

Supaya data yang masuk ke website diambil secara otomatis maka dirancang RFID dan NodeMCU sebagai mikrokontroller yang berbasis IoT [5]. Dengan membangun sistem menggunakan bahasa pemograman javascript dan HTML system dapat dimonitor secara realtime [6]. Penerapan RFID dan Web sangat menghemat waktu karena data yang telah diinput secara otomatis tersimpan dan dapat di baca kembali oleh system melalui tag RFID [7]. Enkripsi data pada algoritma lizard dapat iimplementasikan menggunakan perangkat NodeMCU dengan waktu 1014419 microsecond. Proses enkripsi dilakukan pada saat data akan dikirimkan dan melakukan proses dekripsi pada saat data diterima dari broker [8].

\section{METODE PENELITIAN}


ISSN 2614-5278 (media cetak), ISSN 2548-8368 (media online)

Available Online at https://ejurnal.stmik-budidarma.ac.id/index.php/mib DOI 10.30865/mib.v4i2.1906

\subsection{Kerangka Penelitian}

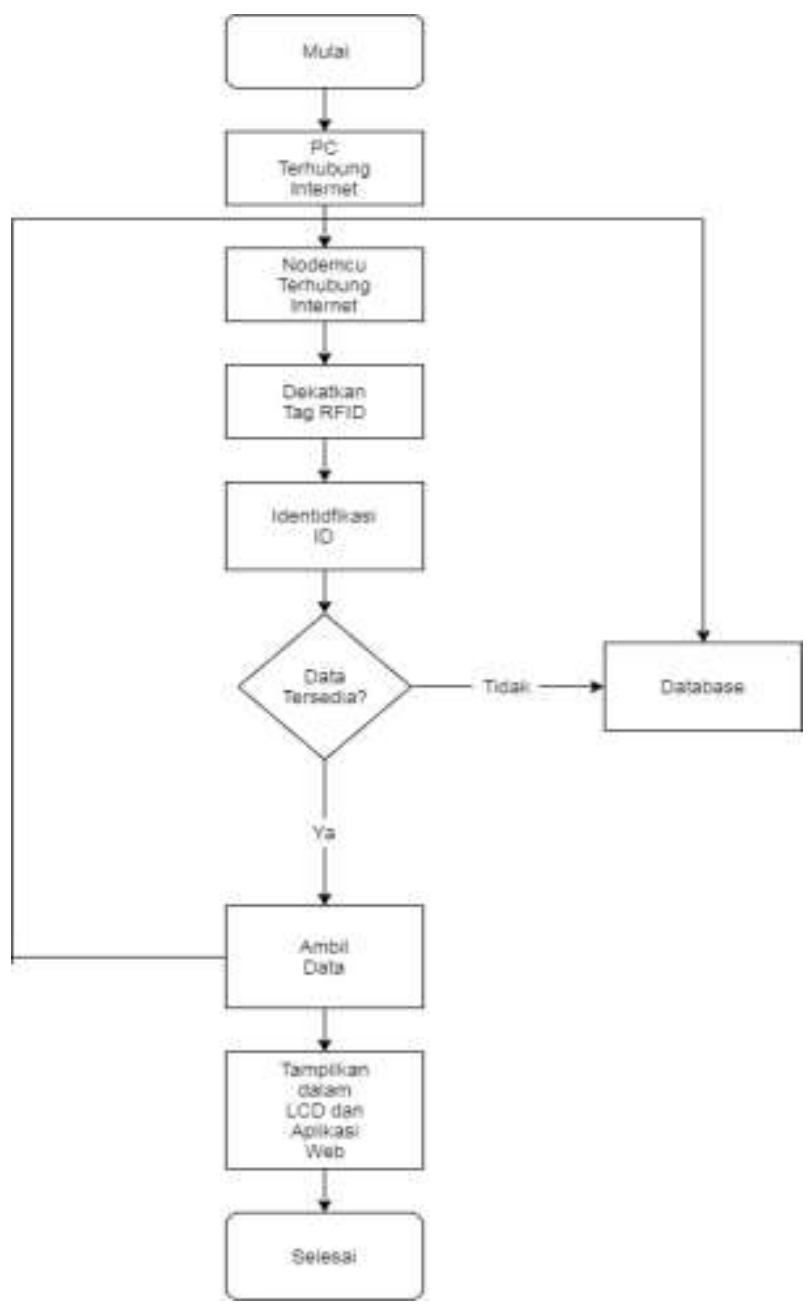

Gambar 1. Flowchart Penelitian

Pada gambar 1 merupakan kerangka penelitian, penjelasan dari kerangka penelitian adalah sebagai berikut:

1. Mulai kemudian pc harus terhubung ke internet.

2. Nodemcu dihubungkan ke wifi dengan menggunakan software arduino IDE.

3. Dekatkan tag RFID ke RFID reader dengan jarak minimal $4 \mathrm{~cm}$ supaya kode desimal teridentifikasi dengan baik.

4. Jika data tidak tersedia data tidak akan ditampilkan ke LCD dan aplikasi web dan jika data tersedia data akan diambil dari database dan ditampilkan ke LCD dan aplikasi web.

\subsection{Desain Server dan Web}

Dalam pengiriman data yang digunakan adalah dengan menggunakan URL Variable. Artinya data yang dikirim ke server dikirim dalam kueri url / suatu alamat situs yang berisi program PHP, yang sudah disesuaikan antara variabel pada pengirim data, dan variabel penerima data. alamat web yang digunakan http://amrikers.000webhostapp.com/proses.php?=ID,pengguna tinggal membuka website, setelah itu website akan menampilkan informasi, sesuai permintaan yang diminta pengguna. Data yang ditampilkan berupa tabel [9].

\section{HASIL DAN PEMBAHASAN}

\subsection{Sistem Kerja}

Sistem kerja dari program adalah bagaimana cara kerja dari sistem yang telah diteliti, sistem kerja programnya yaitu:

1. User atau pengguna melakukan input data tag RFID dengan cara mendekatkan tag ke RFID reader.

2. NodeMCU akan menerima data dari tag RFID melalui reader RFID. 
3. Data berupa decimal diambil dari database MySQL melalui nodeMCU selanjutnya data akan ditampilkan pada LCD dan Dashboard website.

4. DFPlayer Mini akan menerima tegangan dan memutar suara.

Blok diagram alat akan menujukkan konsep dasar dari alat yang dibuat, Pada gambar 1 dapat dilihat blok diagram sistem.

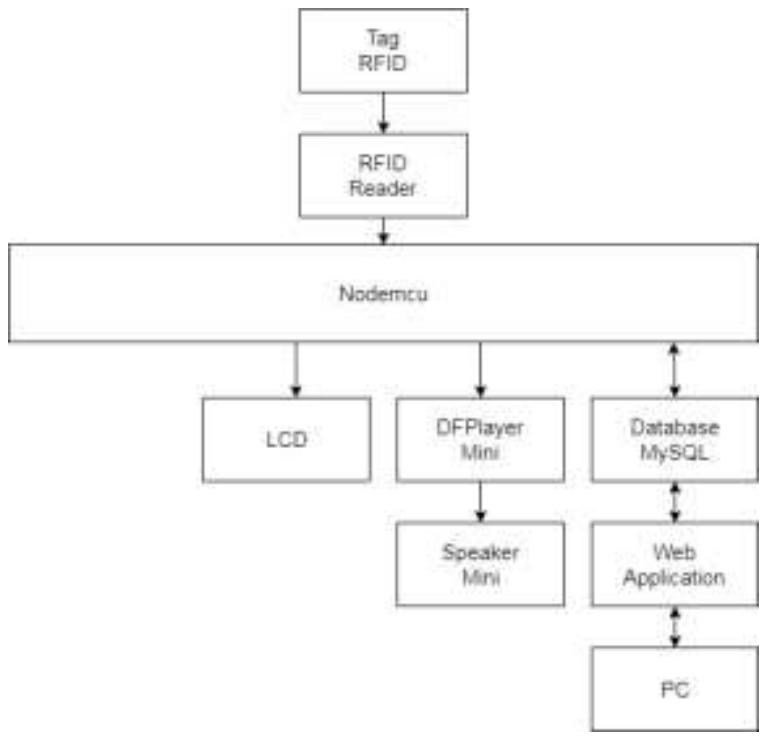

Gambar 1. Blok diagram Sistem

Berdasarkan gambar 1, kita tahu bahwaterdapat sembilan subsistem yang terdapatdalam alat sistem Implementasi RFID dan NodeMCU Untuk Data Kunjungan Perpustakaan Berbasis IoT, Fungsi Sembilan subsistem tersebut adalah sebagai berikut:

1. RFID Reader, fungsi dari subsistem iniadalah untuk membaca ID dan informasiyang ada pada suatu kartu RFID. Pada penelitian ini RFID berfungsi untuk membaca id pada kartu.

2. NodeMCU, fungsi dari subsistem iniadalah sebagai memproses sekaligus sebagai konektivitas antara internetdengan hardware yang dilengkapi denganWiFi. Di penelitian ini, tugas dariNodeMcu adalah sebagai memproses,memperintahkan suatu fungsi dari modulRFID reader, LCD dan DFMini Player,dengan adanya alat NodeMCU ini aplikasi dapat dibuat berbasis IoT yang dapat mengirim data secara otomatis melalui jaringan internet.

3. DFPlayer Mini, fungsi dari subsistem ini adalah sebagai proses pemutar suara yang telah terpasang microSD Card dan diteruskan ke speaker mini, Alat ini akan memainkan suara ketika ditag masuk, keluar .

4. Speaker Mini, Fungsi dari subsistem ini adalah sebagai output yang telah diproses DFMini Player.

5. Liquid Crystal Display (LCD), fungsi darisubsistem ini adalah untuk menyampaikaninformasi seperti informasi masuk anggota, keluar dan informasi tidak terdaftarnya kartu.

6. Database MySQL, fungsi darisubsistem ini adalah untuk menyimpan data-data dari anggota perpustakaan seperti ID, Nama, Npm, Nomor telepon dan Alamat.

7. Web Application, fungsi dari subsistem ini adalah untuk mengelola data-data anggota seperti meregistrasikan anggota, melihat jumlah total anggota, jumlah total kunjungan per hari, jumlah anggota yang sedang berkunjung, menyimpan data anggota ke dalam bentuk PDF.

8. Tag RFID, fungsi dari subsistem ini adalah untuk menyimpan nomor decimal yang ada di dalam kartu tag RFID, kartu tag berfungsi bila di dekatkan pada RFID Reader.

9. PC, fungsi dari pc sebagai mengolah data input dan menghasilkan output berupa data informasi.

Admin melakukan inputan data tag RFID dengan mendekatkan tag ke RFID reader. Reader akan memberikan data ke NodeMCU untuk diproses dan menapilkan data output ke LCD dan Dashboard website. NodeMCU akan melakukan pengolahan data untuk menentukan tindakan selanjutnya, jika NodeMCU terkoneksi jaringan internet maka data dapat diproses dan dapat memasukkan id ke dalam database MySQL melalui aplikasi website. Jika anggota telah terdaftar selanjutnya dapat melakukan tag masuk dengan cara mendekatkan tag ke RFID Reader setelah kartu ditap maka akan ada output berupa informasi "Selamat Datang Silahkan Masuk" dari LCD dan DFMini Player.

Anggota yang terdaftar dan melakukan tap kartu sebanyak 2 kali maka akan ada output LCD berupa "Sampai Jumpa" dan memainkan suara dari DFMini Player mengeluarkan suara "Sampai jumpa silahkan datang kembali" 


\section{JURNAL MEDIA INFORMATIKA BUDIDARMA}

Volume 4, Nomor 2, April 2020, Page 264-270

ISSN 2614-5278 (media cetak), ISSN 2548-8368 (media online)

Available Online at https://ejurnal.stmik-budidarma.ac.id/index.php/mib DOI 10.30865/mib.v4i2.1906

Anggota yang tidak terdaftar NodeMCU akan memerintahkan ke LCD dengan mengeluarkan informasi dengan tampilan "kartu tidak dikenali" dan memainkan suara dari DFPlayer Mini.Di dalam komponen DFPlayer Mini terdapat microsd card yang telah diisi 3 file mp3 yang telah dinamai 001 sampai 003.

\subsection{Perancangan Alat}

Perancangan alat dibuat untuk menghasilkan suatu sistem perangkat keras yang dapat berkomunikasi dengan database. Pada perangkat ini terdapat komponen berupa nodemcu lolin, board nodemcu, LCD 12C, kabel jumper, microsd card, RFID Reader, speaker mini dan DFPlayer Mini. Koneksi pin komponen bisa dilihat pada tabel.

Tabel 1. Koneksi pin Nodemcu -RFID

\begin{tabular}{l|l}
\hline Nodemcu & RFID \\
\hline D3 & RST \\
D4 & SDA \\
D5 & SCK \\
D6 & MISO \\
D7 & MOSI \\
GND & GND \\
3V & $3,3 \mathrm{~V}$ \\
\hline
\end{tabular}

Pada tabel 1 adalah rancangan koneksi pin NodeMCU ke pin RFID, perancangan koneksi ini dibuat untuk menghubungkan RFID Reader ke Nodemcu supaya data yang diambil dari RFID Reader akan diteruskan ke NodeMCU.

Tabel 2. Koneksi Pin Nodemcu - LCD 12C

\begin{tabular}{l|l}
\hline Nodemcu & LCD 12C \\
\hline D2 & SDA \\
D1 & SCL \\
GND & GND \\
VUSB & VCC \\
\hline
\end{tabular}

Pada tabel 2 adalah rancangan koneksi pin NodeMCU ke pin $L C D$ 12C, Kedua alat ini dihubungkan agar $L C D$ $12 C$ dapat menerima dan menampilkan data yang diterima dari NodeMCU.

Tabel 3. Koneksi Pin Nodemcu, DFPlayer Mini dan Speaker Mini

\begin{tabular}{l|l|l}
\hline Nodemcu & DFPlayer & $\begin{array}{l}\text { Speaker } \\
\text { Mini }\end{array}$ \\
\hline D0 & Tx & - \\
D8 & Rx & - \\
GND & GND & - \\
VUSB & VCC & - \\
- & SPK_1 & Merah (+) \\
- & SPK_2 & Hitam (-) \\
\hline
\end{tabular}

Pada tabel 3 adalah rancangan koneksi pin NodeMCU ke pin DFPlayer Mini dan Speaker mini, fungsinya supaya NodeMCU dapat mengirim tegangan ke DFPlayer Mini, dan Speaker Mini. Hasil dari perancangan alat dari tabel 1 sampai tabel 3 dapat dilihat pada gambar 3.

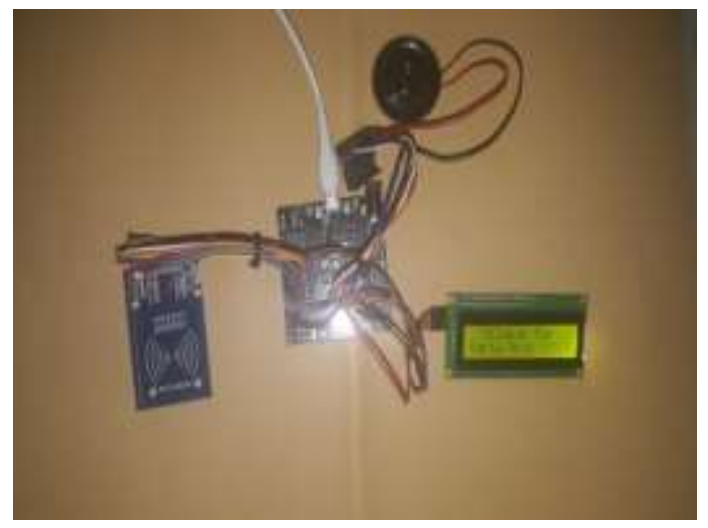

Gambar 3. Hasil Perancangan Alat. 
JURNAL MEDIA INFORMATIKA BUDIDARMA

Volume 4, Nomor 2, April 2020, Page 264-270

ISSN 2614-5278 (media cetak), ISSN 2548-8368 (media online)

Available Online at https://ejurnal.stmik-budidarma.ac.id/index.php/mib DOI 10.30865/mib.v4i2.1906

\subsection{Perancangan Web}

Perencanaan program aplikasi bertujuan untuk membuat agar aplikasi mempunyai user interface yang bagusdan memudahkan pemakai serta bisa berkomunikasi dengan yang sudah di buat, pada aplikasi ini terdapat form login admin, menu dashboard, anggota, registrasi dan pengunjung bisa dilihat pada tabel 3 - tabel 7 .

\section{a. Form Login}

Form login dibuat untuk membatasi akses supaya tidak sembarang orang bisa masuk ke dalamnya, contoh seperti pada gambar 3.
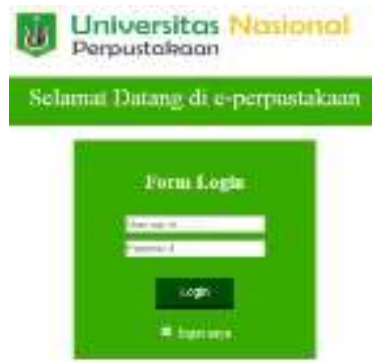

Gambar 3. Form Login

\section{b. Halaman Dashboard}

Halaman dashboard aplikasi web dibuat untuk monitor data anggota yang telah terdaftar, pengunjung yang masuk hari ini dan data anggota yang sedang berkunjung secara real time, Contoh dapat dilihat pada gambar 4 .

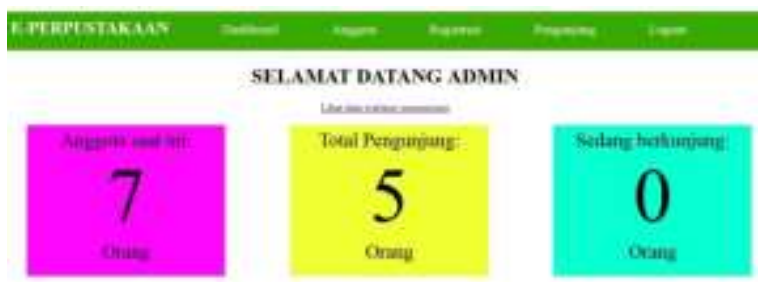

Gambar 4. Halaman Dashboard

\section{c. Halaman Anggota}

Halaman anggota dibuat untuk mengontrol data anggota yang telah terdaftar contohnya seperti mengedit, hapus, simpan data ke dalam bentuk exel dan PDF, Contoh dapat dilihat pada gambar 5.

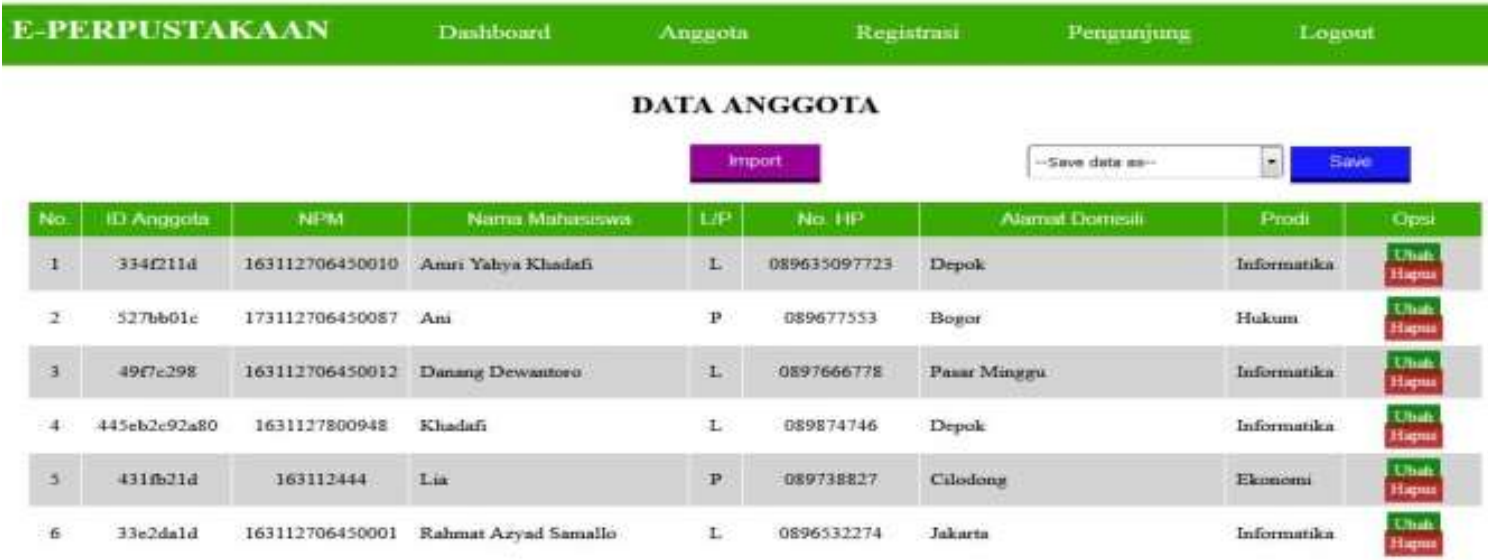

Gambar 5. Halaman Data Anggota

\section{e. Halaman Registrasi}

Pada halaman ini admin dapat meregistrasi data anggota menggunakan tag rfid, Angka desimal muncul ke id anggota secara otomatis jika ditap ke RFID reader dan admin dapat menyimpan data setelah melakukan proses registrasi, Contoh bisa dilihat pada gambar 6. 
ISSN 2614-5278 (media cetak), ISSN 2548-8368 (media online)

Available Online at https://ejurnal.stmik-budidarma.ac.id/index.php/mib DOI 10.30865/mib.v4i2.1906

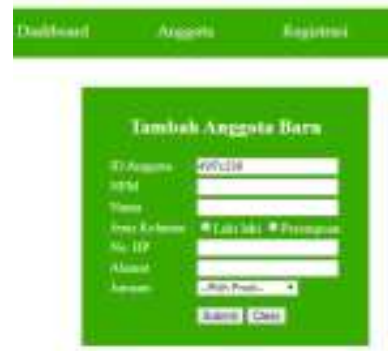

Gambar 6. Halaman Form Registrasi

\section{f. Halaman Pengunjung}

Pada halaman pengunjung admin dapat memonitor siapa saja yang masuk ke dalam perpustakaan secara realtime tanpa harus merefresh page browser.

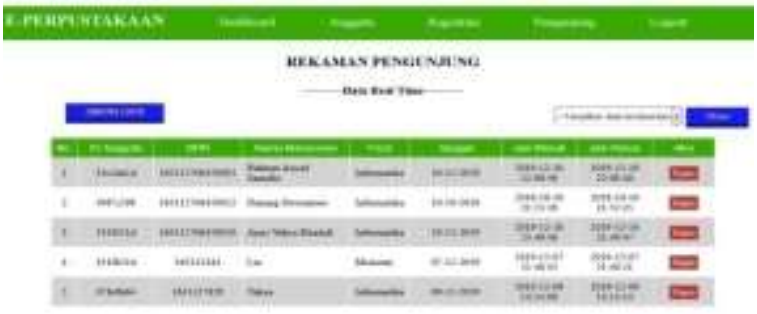

Gambar 7. Halaman Pengunjung

\section{g. Halaman Simpan Data}

Pada halaman simpan data admin dapat menyimpan data pengunjung berdasaran tanggal, bulan dan tahun contoh pada gambar 8 .

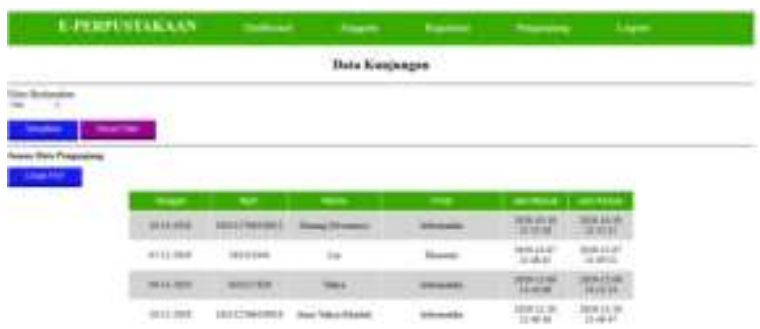

Gambar 8. Halaman Simpan Data

\subsection{Pengujian tag RFID ke aplikasi}

Data hasil pengujian jenis tag RFID ke aplikasi dapat dilihat pada tabel 4

Tabel 4. Pengujian tag RFID ke aplikasi

\begin{tabular}{|c|c|c|}
\hline Input & output & Hasil \\
\hline $\begin{array}{l}\text { Tap kartu untuk registrasi } \\
\text { Tap kartu masuk } \\
\text { Tap kartu keluar }\end{array}$ & $\begin{array}{l}\text { Menampilkan ID ke form registrasi } \\
\text { Menampilkan data kunjungan masuk perustakaan } \\
\text { Menampilkan output keluar dari data anggota yang masuk } \\
\text { sebelumnya }\end{array}$ & $\begin{array}{l}\text { Berhasil } \\
\text { Berhasil } \\
\text { Berhasil }\end{array}$ \\
\hline
\end{tabular}

Pada tabel 4 merupakan tabel pengujian tag RFID ke aplikasi dengan cara menempelkan tag ke RFID Reader. Data hasil pengukuran jarak RFID tag dapat dilihat pada tabel 5.

Tabel 5. Jarak tag RFID

\begin{tabular}{l|l}
\hline Jarak Ukur & Terdeteksi/Tidak terdeteksi \\
\hline $0 \mathrm{Cm}$ & Terdeteksi \\
$1 \mathrm{Cm}$ & Terdeteksi \\
$2 \mathrm{Cm}$ & Terdeteksi \\
$3 \mathrm{Cm}$ & Terdeteksi \\
$4 \mathrm{Cm}$ & Terdeteksi \\
\hline
\end{tabular}




\begin{tabular}{l|l}
\hline Jarak Ukur & Terdeteksi/Tidak terdeteksi \\
\hline $5 \mathrm{Cm}$ & Tidak terdeteksi \\
\hline
\end{tabular}

Pada tabel 5 adalah penelitian jarak tag RFID ke RFID Reader yang mempunyai batas jarak dari 0 Cm sampai 5 $\mathrm{Cm}$.

\subsubsection{Pengujian Komunikasi Alat Dengan Database}

Dari beberapa kali percobaan alat dapat berkomunikasi dengan database dan aplikasi website dan waktu pengiriman data atau menerima data dari database tergantung pada kecepatan internet. Dari pengujian ini dapat dilihat pada tabel 9 .

Tabel 6. Ujicoba Alat

\begin{tabular}{l|l|l}
\hline No & Pengujian & Hasil \\
\hline 1 & NodeMCU terkoneksi internet & Sukses (3 detik) \\
2 & Pc terkoneksi internet & Sukses (2 detik) \\
3 & RFID reader dapat menerima data dari tag & Sukses (1 detik) \\
4 & NodeMCU dapat mengirim data ke database & Sukses (1 detik) \\
5 & Alat dapat menerima data dari tag dan menampilkan output di LCD & Sukses (2 detik) \\
6 & Aplikasi website dapat menampilkan data yang diambil dari database & Sukses (1 detik) \\
7 & DFMini Player memutar suara setelah mendapat perintah dari NodeMCU & Sukses (2 detik) \\
\hline
\end{tabular}

\section{KESIMPULAN}

Setelah melakukan perencanaan dan pembuatan sistem yang kemudian dilakukan pengujian, maka peneliti dapat mengambil kesimpulan sebagai berikut:

1. Pembacaan tag RFID dapat digunakan atau dimanfaatkan sebagai penyimpan informasi yang lebih banyak dan tag RFID lebih efektif karena dapat dibawa kemana-mana dan sangat sulit untuk diduplikasi.

2. Dengan menggunakan bahasa pemograman javascript data yang diambil dapat ditampilkan secara realtime tanpa harus merefresh page browser.

3. Komunikasi dalam mengirim data ataupun menerima data tergantung dari kecepatan internet.

\section{REFERENCES}

[1] A. Kurniawan, D. Syauqy, and B. H. Prasetio, "Pengembangan Sistem Monitoring Listrik Pada Ruangan Menggunakan NodeMCU dan MQTT," J. Pengemb. Teknol. Inf. dan Ilmu Komput. Univ. Brawijaya, vol. 1, no. 6, pp. 486-491, 2017.

[2] A. Warda, P. Putra, A. Bhawiyuga, and M. Data, "Implementasi Autentikasi JSON Web Token ( JWT ) Sebagai Mekanisme Autentikasi Protokol MQTT Pada Perangkat NodeMCU," J-Ptiik, vol. 2, no. 2, pp. 584-593, 2018.

[3] Y. Maryono and I. Darwati, "Perancangan Web Perpustakaan Pada Smp Taruna Bhakti Depok," None, vol. 13, no. 2, pp. 239-244, 2017.

[4] D. Pratiwi ${ }^{1}$ et al., "Rancang Bangun Sistem Informasi Perpustakaan Pada Sekolah SMK Yadika 13 Tambun Utara Berbasis Web," vol. XX, no. 1, pp. 53-58, 2018.

[5] B. A. Prasetya, "Rancang Bangun Prototype Kendali Pintu Kantor Berbasis Rfid Dan Iot," pp. 1-10, 2019.

[6] D. Satria, S. Yana, R. Munadi, and S. Syahreza, "Sistem Peringatan Dini Banjir Secara Real-Time Berbasis Web Menggunakan Arduino dan Ethernet," J. JTIK (Jurnal Teknol. Inf. dan Komunikasi), vol. 1, no. 1, p. 1, 2017, doi: 10.35870/jtik.v1i1.27.

[7] P. Adi and B. Web, "PENERAPAN RADIO FREQUENCY IDENTIFICATION," pp. 1169-1178, 1978.

[8] R. Dismantoro, A. Kusyanti, and M. Data, "Implementasi Algoritme Lizard untuk Pengamanan Protokol MQTT pada Perangkat NodeMCU,” J. Pengemb. Teknol. Inf. dan Ilmu Komput. Univ. Brawijaya, vol. 2, no. 12, pp. 6447-6456, 2018.

[9] I. A. Saputro, J. E. Suseno, and C. E. Widodo, "Rancang bangun sistem pengaturan kelembaban tanah secara real time menggunakan mikrokontroler dan diakses di web," Youngster Phys. J., vol. 6, no. 1, pp. 40-47, 2017. 